\title{
Qualities of knowledge brokers: reflections from practice
}

\author{
David Phipps and Sarah Morton'
}

Employing knowledge brokers is one way that universities and research centres have responded to the increasing emphasis on the wider usefulness and uptake of research beyond the academy. While there is an increase in the numbers of such professionals, there has been little focus on their roles, skills and development. In this paper, two knowledge exchange directors from Canada and the United Kingdom reflect on their combined experiences of being, developing and employing knowledge brokers in a range of roles.

\section{Introduction}

Knowledge exchange is increasingly becoming part of the fabric of university life as universities, university-based researchers and their non-academic research partners seek to maximise the impact of research on public policy and professional practice. In Canada and the United Kingdom (UK), funding councils require applicants to articulate how the funded research will have an impact beyond traditional scholarly dissemination and how it will benefit wider society. In the UK, the upcoming Research Excellence Framework (HEFCE, no date) is an additional driver as it will include assessments of the extra-academic (Donovan, 2007) impact of university research. Phipps and Shapson (2009) have previously written that knowledge mobilisation ${ }^{2}$ (the process) enables social innovation (the outcome). If extra-academic impact is the desired outcome then knowledge exchange (KE) and associated activities are processes that might help to maximise this impact. Knowledge brokers (KBs) are sometimes employed as a way of furthering this agenda, and have been key to success in some initiatives (Nutley, 2003; Rigby, 2005).

Previous reflections on KBs have focused on their roles in the context of Scottish university research centres (Knight and Lightowler, 2010) or in the Canadian health system (CHSRF, 2003; Lomas, 2007). Ward et al (2009) described some of the skills that KBs needed to bring the 'two communities' of research and policy/practice together, and this 'two communities' thesis has been a popular way of conceptualising the problems of research utilisation, seeing them as separated by mutual misunderstandings, and differing timescales and priorities (Caplan, 1977; Cousins and Simon, 1996). However, it is our experience that policy and academic communities can and do collaborate and co-create useful knowledge, working in a shared space alongside others from a variety of settings. This more optimistic view acknowledges that rather than two communities, there are multiple players working to produce, use and channel research. The concepts of 'knowledge transfer' and 'bridging the gap between the 
two communities' are less applicable than the language of knowledge exchange or mobilisation, implying this more interactive approach (Davies et al, 2008; Morton and Nutley, 2011). We see that the role of the KB, rather than bridging a gap between two communities, is to create and work in this shared collaborative space.

Early work by the Canadian Health Services Research Foundation (CHSRF, 2003) reviewed the knowledge management literature and identified specific KB skill sets, but also recognised important qualities for this role such as imagination, intuition, an inquisitive nature and the ability to be an inspirational leader. Bowen and Marten (2005: 209) cited personal factors as being key to effective knowledge translation but that 'the importance of personality has not received sufficient attention'. Recently, Stetler et al (2011) published a revised PARiHS (Promoting Action on Research Implementation in Health Services) framework, identifying a number of qualities that are important for facilitation including:

- $\quad$ authenticity, realness and openness;

- $\quad$ respect and general credibility;

- accessibility, approachability and empathy;

- flexibility;

- responsiveness and reliability;

self-confidence.

The PARiHS framework has never been evaluated in practice (Stetler et al, 2011) but is meant to be applied to situations where health evidence is being implemented into practice. PARiHS has not been applied to broader ideas of knowledge exchange where researchers and decision makers are collaborating to co-create evidence, particularly in the social sciences, that might be implemented to inform social policies or social services.

\section{Context: who we are}

David Phipps is the director of research services and knowledge exchange for York University (Toronto, Canada). As part of this portfolio he directs the Knowledge Mobilization (KMb) Unit, the first Canadian KMb Unit that is fully integrated into the university's research infrastructure. The sole mandate of the KMb Unit is to broker relationships between York's researchers/students and non-academic research partners (primarily from the community sector and regional/municipal governments) so that York's research can have an impact on public policy and professional practice. David Phipps has 15 years of experience working to broker relationships between university research and non-academic partners. For seven years he worked in technology transfer in universities and government positions and has been leading York's technology transfer activities and KMb Unit since 2003.

Sarah Morton is the co-director (knowledge exchange) at the Centre for Research on Families and Relationships (CRFR) based at the University of Edinburgh, a multi-university research centre set up with a remit to make research accessible to non-academics and to create dialogue between research, policy and practice. Over 10 years, CRFR has emerged as a KE leader, with work being recognised by the 
main UK funding bodies. Sarah's background is in multi-sector networking and development roles, and as well as directing the CRFR KE team she is KE Specialist to the Scottish School of Public Health Research, KE adviser to the UK Centre for Population Change and a research impact analyst.

The positions described above both involve directing $\mathrm{KE}$ activities for our respective institutions. Unlike the KB roles described by Knight and Lightowler (2010), we each lead a complement of KB.The focus of these posts is solely on brokering - there is no ambiguity of role nor are their roles research/KE hybrids as described by Knight and Lightowler (2010). Both York University's KMb Unit and the CRFR with partners across Scottish universities, broker relationships between academic researchers and non-academic decision makers to enable the creation and use of evidence that not only informs public policy and professional practice but may also be disseminated through traditional scholarly channels.

This practice-based paper presents reflections on our combined 28 years of experience working as KBs and now as directors of teams of brokers we seek to compare the qualities of KBs to illustrate those personal characteristics that we see common to effective KBs. We hope that this will help other KE units and academic centres to attract and retain individuals who will succeed in their KB roles.

A comparison of the KMb Unit and CRFR is shown in Table 1.

\section{Table I:A comparison of York's KMb Unit and CRFR}

\begin{tabular}{|c|c|c|}
\hline$\frac{0}{6}$ & York & CRFR \\
\hline Location & University-wide & Inter-university \\
\hline $\begin{array}{l}\text { Scope } \\
\text { C } \\
\end{array}$ & Non-specific & $\begin{array}{l}\text { Families and relationships across } \\
\text { the lifecourse }\end{array}$ \\
\hline Institutional support & Core institutional budget & Grant and indirect cost funding \\
\hline Main model for KE & Co-creation & $\begin{array}{l}\text { Interactive, supportive, } \\
\text { partnership approaches }\end{array}$ \\
\hline Engage in research & No & Yes \\
\hline Institutional mandate & Yes & $\begin{array}{l}\text { Initial funding and mandate from } \\
\text { the main Scottish university } \\
\text { funder }\end{array}$ \\
\hline $\begin{array}{l}\text { Number of full-time equivalent } \\
\text { staff }\end{array}$ & 3 & $4.4(\mathrm{KE})$ \\
\hline University authority & VP Research \& Innovation & $\begin{array}{l}\text { Collaborative steering group } \\
\text { made up of all university } \\
\text { partners }\end{array}$ \\
\hline Principal audiences & $\begin{array}{l}\text { Policy makers and practitioners } \\
\text { in the community and local } \\
\text { authorities }\end{array}$ & $\begin{array}{l}\text { Policy makers and practitioners } \\
\text { in health, education, and social } \\
\text { work and across government, } \\
\text { local government and the } \\
\text { voluntary sector }\end{array}$ \\
\hline
\end{tabular}

Despite the differences in CRFR and the KMb Unit the mandates of the two units are similar. In the framework of Oldham and McLean (1997), our KBs are mostly linkage agents working in a transactional framework although the emphasis is on partnership and co-production models as opposed to bridging two discrete communities. 


\section{What we did}

Over the KMb Unit's five years and the 10 years of CRFR we have recruited a total of $16 \mathrm{KBs}$ and currently maintain supervision of $7.4 \mathrm{KBs}$. We have the track record to compare KBs working with similar mandates in different institutional settings. This unique perspective allows us to reflect on the qualities of those we have hired. We reviewed 13 job descriptions we had previously prepared for various $\mathrm{KB}$ roles. As described, the majority of these jobs were for linkage roles to support KE, although early job descriptions at the $\mathrm{KMb}$ Unit focused more on making existing research findings accessible to decision makers. Each job description presents desired skills as well as desired attributes and qualities.

We also asked four current KBs (two KMb Unit, two CRFR) to reflect on their experiences as professional KBs and answer the single question, 'I think I am a good $\mathrm{KB}$ because..... The results of this were first presented at a KB workshop in London, UK on 7 December 2011 (Morton and Phipps, 2011), which was funded by the Economic and Social Research Council.

The personal qualities of KBs presented below are based on the job descriptions and our own and our KB teams' reflections. Each quality is associated with an image and is exemplified by an example from one of our KE practices. It is important to note that each of the University of York's and CRFR's KBs has academic (graduate student) credentials to ensure that they are able to understand and interpret research, along with non-academic experience working in community, policy or practice settings (eg, literacy services, Aboriginal services, local or regional government projects or non-governmental organisation projects). This extra-academic experience contributes to their credibility when working with non-academic agencies and also enables them to have empathy with and an appreciation of both the academic and community/policy/practice experience.

We observe from our own work and by observing attendees at KE workshops and conferences that $\mathrm{KB}$ roles are dominated by women in both Canada and the UK. This may reflect differing career paths and status, but we suggest that it also reflects that the qualities outlined may be more comfortably developed in women than men.

\section{Qualities of KBs}

\section{Nimble, fleet footed image: Mercury - roman god with winged sandals}

Working in KE often means informal-style meetings with multiple stakeholders. KBs need to be able to react to whatever they see in front of them when meeting with partners from diverse sectors. There is often a high rate of change, varying commitment to the KE agenda and different personnel at different meetings. The ability to be able to make quick decisions, react to changing agendas and still keep hold of the KE mission is important. 
For example, in one of CRFR's multi-stakeholder projects, a small working group had developed a funding proposal. By the time this was presented to the larger group, members had forgotten what the original objective was, membership had changed and stakeholders were uncertain that they liked the new direction the project was taking. The $\mathrm{KB}$ had to take all of this on board very quickly and then sell the project back to the group. Being aware of the individual members' sensitivities and agendas is an important part of being able to do this successfully

\section{Enthusiastic}

\section{Image: cheerleader}

Often the $\mathrm{KB}$ is the only person who is interested in creating a shared agenda between partners. They have to sell the idea to the different stakeholders and enthusiasm is important in getting others on board. When questioned, $\mathrm{KB}$ in our teams reflected that they are passionate about their work linking research to the 'real' world, and bringing people together to share an agenda. York's KMb Unit invests significant amounts of time off-campus, working in the community to promote research collaborations with the university. We have recently placed a KB at the United Way of York Region,York Region's principal community agency, a community-based 'cheerleader' to enhance our presence in the community. As one KB commented "I am interested in research and enjoy speaking and writing about it."

\section{Creativity}

\section{Image: artist}

There is not always an obvious course of action when working in a $\mathrm{KB}$ role. Sometimes there is the need to come up with new ways of working, new approaches to communication or other creative solutions to problems. For example, CRFR developed an action-planning process to encourage voluntary organisations to engage with creating channels for research evidence to influence family services delivery as part of the About Families Project. The KMb Unit's Mobilizing Mind project is a collaboration between universities, mental health practitioners, community mental health agencies and young adults, some with lived experience of mental health challenges. In order to speak to the young adults about mental health, the KB wrote a knowledge mobilisation rap presenting complex concepts in a format accessible to the young adults. The rap is posted on a mental health poetry website (Phipps, 2009).

\section{Communicator, listener and supporter Image: therapist}

The KB role is part leader, part supporter. Our KBs reflected that they support and build confidence with academics to help them go and share their work, to become more aware of the needs of others. In supporting stakeholders it is about building their confidence in talking about and using research, accessing information and researchers. Often the role is facilitating, and many commented that it is about building capacity 
rather than serving self-interests. For example, CRFR KBs support research staff in dealing with the press, helping them work up press statements and holding their hand (sometimes literally!) while they talk to the press. In the KB's own words: "I bring a lot of respect of other organisations' needs. I am a good listener and I put them at the centre of my work."

\section{Courage}

\section{Image: tightrope walker}

Often a KB works in the space between different organisations and individuals and they have to be able to lead in that space. Rather than walking a tightrope between two communities they need to have the courage to step ahead and encourage others to follow - the courage to try new things, make suggestions and maintain momentum and enthusiasm when others are less sure. For example, working for a new collaboration of academics with little experience of KE, a KB from CRFR sold them the idea of a reception in the Scottish Parliament, and then had to make sure it worked for all parties concerned. Social media can be daunting to many researchers, non-academic partners and KBs. York started blogging in 2008, tweeting in 2009 and also began to explore online collaboration tools in 2009. Social media and on line collaboration tools are now standard tools for York's KMb Unit (Phipps, 2011).

\section{Tact and negotiation}

\section{Image: scales of justice}

As reflected in the discussion above, a KB role is about balancing competing agendas and creating shared directions. This might mean working for different task-masters simultaneously, which can create difficulties in overcoming power differentials, and balancing competing agendas. This can result in time management issues, and it can be difficult to balance the competing demands of academics and stakeholders. On the positive side, this work is also about showing how each organisation can contribute and offers continuous opportunities to learn. As described by Phipps (2011), KM in the AM (breakfast meetings on knowledge mobilisation) research forums create equity between the academic and non-academic audiences by holding KM in the AM off campus and having a community speaker and an academic speaker at each event. "I feel passionate about sharing and using knowledge; I enjoy building trusting and supportive relationships."

\section{Tireless commitment Image: athlete}

Knowledge brokering takes energy and commitment because collaboration is harder and more time consuming than individual research. The KMb Unit facilitated a meeting between a York University professor and someone from the Canadian Mental Health Association of York Region in December 2006. It took two years to secure a five-year, CAD $\$ 1.5$ million grant to create the project 'Mobilizing Minds: 
pathways to young adult mental health'. The relationship, the funding process and the project are supported by York's KMb Unit. CRFR spent 12 months negotiating a partnership research programme with ChildLine Scotland. Although this took a long time to develop, the project resulted in the successful funding of two research projects and wide impacts on policy and practice. Having a personal angle to this commitment can help, as described by a KB: "Knowledge mobilisation aligns well with my own personal ethics. It is important that research is used for public good."

\section{Figure I: Idealised knowledge broker}

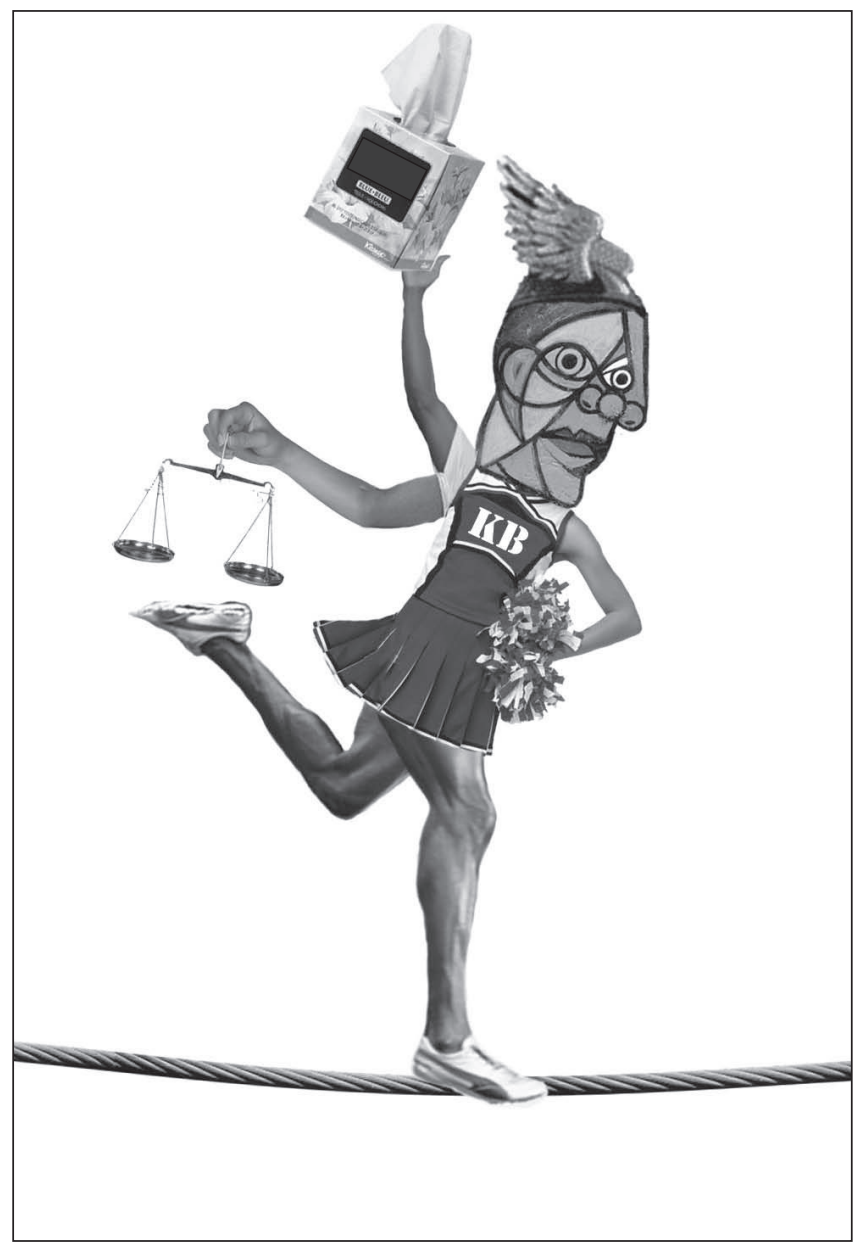

(C) Dawn Cattanach 2013

The list of qualities above prompted nods, laughs and discussion when we shared it with KBs at the 'Bridging the Gap' Genomics Policy and Research Forum (see Morton and Phipps, 2011), CRFR's KE community of practice and with other KB colleagues in our institutions. Putting all of the qualities together looks daunting. 
While not all qualities will necessarily be practised by all KBs in all knowledge exchange situations, we nonetheless suggest that while there might be emphasis on some qualities more than others for $\mathrm{KB}$ roles in different settings, a basic ability across all of the qualities is important for KBs' successful relationship building. Building a team that between them can cover the qualities listed, as long as there is flexibility to allocate work accordingly, might be one way forward.

\section{Recruiting and training for KBs}

How can a better understanding of these qualities help develop KB roles and the ways these are supported and further developed? We found some commonalities among the job descriptions we use to recruit, for example communication skills, and experience of working with multiple stakeholders, which reflect the qualities above. Keeping the list of qualities in mind during the recruitment process, and discussing them with stakeholders, can help to ensure that the right people fill $\mathrm{KB}$ vacancies, and the processes of Knowledge Brokering and Mobilization (KBM) are transparent. Further thought about how we help KBs to continually develop these qualities, and sustain their enthusiasm and commitment over time is required, in terms of both organisational support and developing evaluation to ensure feedback. Evaluation of KB work can help to sustain enthusiasm and commitment by demonstrating the difference made by KB work, and providing feedback in relation to the other qualities listed here. As detailed below we provide training and offer support to our KB teams, and create opportunities for them to share experiences and practice. The aim is to develop appropriate skills and qualities, and to foster learning. Further reflection on these qualities of KBs in other settings could help to develop our understanding of these emerging roles.

Srevious literature (Knight and Lightowler, 2010; CHSRF, 2003) has identified training as important for KBs. We agree and note that six out of eight of our KBs had some form of training provided during their role. Some of this is task-specific training such as York's workshops in clear language writing and design, or CRFR training in effective communication for non-academic audiences. We are also responding to training needs by creating some capacity-building workshops in social media and programme evaluation (KMb Unit) and providing listening and networking skills training at CRFR. However, training specifically for knowledge mobilisation or exchange remains fairly underdeveloped.

Training is important for KB skills but training does not develop KB qualities. The seven qualities outlined in this discussion are important from what we have observed in our KE practice. We hire for these qualities and provide training opportunities to develop specific skills. In addition, we have encouraged the development of community of practice-type development opportunities for staff, through the Canadian Knowledge Transfer and Exchange Community of Practice, the 'Practice what you preach' KE reading group at CRFR and the establishment of a Scottish KE Community of Practice. As an emerging profession it is important to be able to develop and share practice and these provide an opportunity to do this, which we have found invaluable and difficult to access elsewhere. For both of our units, having a 
group of KBs working together rather than the more common experience of a single $\mathrm{KB}$ working in a research project or unit can help to overcome some of the isolation often associated with these kinds of roles, as discussed by Knight and Lightowler (2010). Until the profession is more developed, the opportunity to share emerging successes and challenges will be important in developing and understanding what it means to be a $\mathrm{KB}$ and what training might support the development of suitable skills and qualities.

\section{Conclusion}

Despite differences between the KMb Unit and CRFR, the personal qualities of our KBs are similar and reflect the main goal of each unit to form and maintain relationships to support $\mathrm{KE}$ and co-creation of knowledge between researchers and decision makers. It is likely that these qualities will be important for recruiting KBs in a variety of institutional and/or research centre settings as well as for KBs working outside of the academy. Relative emphasis on different skills might vary in relationship to the extent to which individual $\mathrm{KB}$ roles are to broker relationships for the cocreation of research, or to communicate the findings from research that is completed. However, in our experience the qualities are common while specific skills might vary.

$\mathrm{KB}$ is emerging as a profession. While many individuals have a role to play in the cycle of research to action, it seems to us that there is a need for specific roles for KBs with specialist qualities and skills to support effective relationships that enable CO-creation and KE to inform decision making. This activity should not be left to researchers or decision makers to do it 'off the side of their desk', as often this approach means a much lower uptake of research. KE is a legitimate activity that needs to be funded and supported by skilled professionals with training and the right personal qualities. As qualities of $\mathrm{KB}$ become more established and $\mathrm{KB}$ roles become more defined, directors of $\mathrm{KE}$ activities will be increasingly expected to hire the right people for the right job and train and retain excellent staff. This will allow the KB profession to develop, create more mentors trained by accredited courses and create more effective KB practices, ultimately maximising the impact of research on public policy and professional practice.

\section{Notes}

${ }^{1}$ Corresponding author.

${ }^{2}$ A brief note on terminology. York University uses the term 'knowledge mobilisation'. The Centre for Research on Families and Relationships (CRFR) uses the term 'knowledge exchange'. We see these as equivalent terms and chose to use knowledge exchange for the purposes of this paper, while acknowledging that knowledge mobilisation is the preferred term for York University's unit.

\section{Acknowledgements}

With thanks to Michael Johnny, manager, knowledge mobilization, and Krista Jensen, knowledge mobilisation officer, at York University; and Karen Mountney, project manager, Lesley Kelly, Growing up in Scotland (GUS) dissemination officer, and Katrina 
Reid, development officer, at CRFR. Thanks also to Dawn Cattanach for work on our knowledge broker image.

\section{References}

Bowen, S. and Martens, P. (2005) 'Demystifying knowledge translation:learning from the community', Journal of Health Services Research and Policy, 10 (4): 203-11.

Caplan, N. (1977) 'The use of social research knowledge at the national level', in C.H. Weiss (ed) Social research in public policymaking, Lexington, MA: Lexington Books, 183-97.

CHSRF (Canadian Health Services Research Foundation) (2003) The theory and practice of knowledge brokering in Canada's health system, Ottawa: CHSRF, www.chsrf. ca/migrated/pdf/Theory_and_Practice_e.pdf

Cousins, J.B. and Simon, M. (1996) 'The nature and impact of policy-induced partnerships between research and practice communities', Educational Evaluation and Policy Analysis, 18 (3): 199-218.

Davies, H., Nutley, S. and Walter, I. (2008) 'Why "knowledge transfer" is misconceived for applied social research', Journal of Health Services Research and Policy, 13 (3): 188-90.

Donovan, C. (2007) 'The qualitative future of research evaluation', Science and Public Policy, 34 (8): 585-97, doi: 10.3152/030234207X256538.

HEFCE (Higher Education Funding Council for England) (no date) Research Excellence

Framework, Bristol and London: HEFCE, www.hefce.ac.uk/research/ref/

Knight, C. and Lightowler, C. (2010) 'Reflections of "knowledge exchange professionals" in the social sciences: emerging opportunities and challenges for university-based knowledge brokers', Evidence \& Policy, 6 (4): 543-56.

Lomas, J. (2007) 'The in-between world of knowledge brokering', British Medical Journal, 334 (7585): 129-32.

Morton, S. and Nutley, S. (2011) 'What happens next? Getting research into policy and practice', in L. Jamieson, R. Lewis and R. Simpson (eds) Researching families and relationships: Reflections on process, New York, NY: Palgrave Macmillan.

Morton, S. and Phipps, D.J. (2011) 'What makes a good knowledge broker? Reflections on qualities and skills', presentation at 'Bridging the gap between research, policy and practice: the importance of intermediaries (knowledge brokers) in producing research impact', ESR C Genomics Policy and Research Forum, London, UK, 7 December.

Nutley, S. (2003) Increasing research impact: Early reflections from the ESRC Evidence Network, ESRC UK Centre for Evidence Based Policy and Practice: Working Paper 16, St Andrews: Research Unit for Research Utilisation, Department of Management, University of St Andrews.

Oldham, G. and McLean, R. (1997) Approaches to knowledge brokering, Winnipeg: International Institute for Sustainable Development, www.iisd.org/pdf/2001/ networks_knowledge_brokering.pdf

Phipps, D. (2011) 'A report detailing the development of a university-based knowledge mobilization unit that enhances research outreach and engagement', Scholarly and Research Communication, 2 (2): 020502, 13 pp, www.src-online.ca/index.php/src/ article/viewFile/31/57 
Phipps, D.J. (2009) KM rap: Mobilizing minds, http://web.mac.com/peterlevesque/ Mentalhealthpoetry/Poems/Entries/2009/10/7_KM_Rap\%3A_Mobilizing_ Minds_by_Dr._David_Phipps.html

Phipps, D.J. and Shapson, S. (2009) 'Knowledge mobilisation builds local research collaborations for social innovation', Evidence \& Policy, 5 (3): 211-27.

Rigby, E. (2005) 'Linking research and policy on Capitol Hill: insights from research brokers', Evidence \& Policy, 1 (2): 195-214.

Stetler, C.B., Damschroder, L.J., Helfrich, C.D. and Hagedorn, H.J. (2011) 'A guide for applying a revised version of the PARIHS framework for implementation', Implementation Science, 6: 99, www.implementationscience.com/content/6/1/99

Ward, V., House, A, and Hamer, S. (2009) 'Knowledge brokering: the missing link in the evidence to action chain', Evidence \& Policy, 5 (3): 267-79.

\section{David Phipps}

Research Services and Knowledge Exchange, York University, Toronto, Canada dphipps@yorku.ca

\section{Sarah Morton}

Centre for Research on Families and Relationships, University of Edinburgh, UK s.morton@ed.ac.uk 